\title{
Role of Vitamin D in Premature Atherosclerosis in Adolescents Type 1 Diabetes through Transforming Growth Factor- $\beta 1$, Interferon- $\gamma$, Interleukin-10, and Interleukin-17
}

\author{
Harjoedi Adji Tjahjono ${ }^{1,2,3 *}$, Wisnu Barlianto ${ }^{2,3}$, Dian Handayani ${ }^{4}$, Handono Kalim $^{5}$ \\ ${ }^{1}$ Doctoral Program of Medical Science, Faculty of Medicine Universitas Brawijaya, Malang, Indonesia; ${ }^{2}$ Saiful Anwar Hospital, \\ Malang, Indonesia; ${ }^{3}$ Department of Pediatric, Faculty of Medicine Universitas, Brawijaya, Malang, Indonesia; ${ }^{4}$ Nutrition Science \\ Program, Medical Faculty, Universitas Brawijaya, Malang, Indonesia; ${ }^{5}$ Department of Internal Medicine, Faculty of Medicine, \\ Universitas Brawijaya, Malang, Indonesia
}

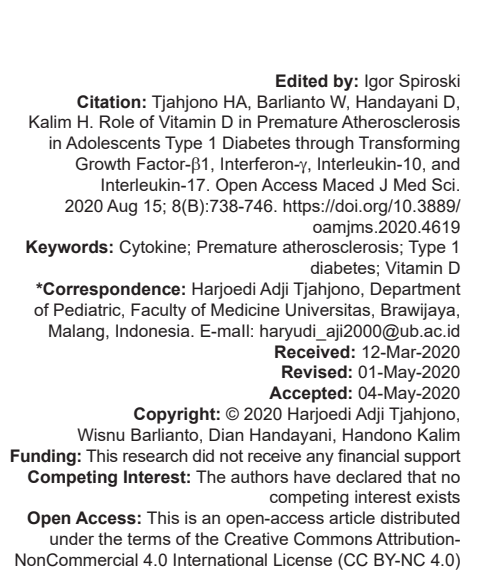

\section{Introduction}

Type 1 diabetes (T1D) is caused by insulin deficiency and predominantly occurred in the pediatric population. International Diabetes Federation estimates as many as 1.1 million children and adolescents will be affected by T1D [1]. In Indonesia, the incidence of T1D was approximately $0.2-0.42$ per 100.000 children in 2012 [2]. The primary cause of mortality in T1D is cardiovascular disease (CVD) [3]. Evidence from the prospective study showed that T1D patients have a higher risk for the development of myocardial infarction, stroke, and heart failure compared to non-diabetic patients [4].

The increased risk of T1D-associated CVD cannot be described adequately by traditional risk factors (dyslipidemia, hypertension, smoking, and age) and microvascular complications, including nephropathy and neuropathy [2], [3], [4], [5], [6]. The possible explanation for CVD, particularly atherosclerosis, in patients with T1D might be linked to endothelial dysfunction, which is strongly associated with oscillating hyperglycemia and oxidative stress [3], [7], [8], [9]. Moreover, in T1D, absolute insulin deficiency also leads to elevated lipolytic activity, causes a release of pro-atherogenic lipoprotein (very low-density lipoprotein [LDL], intermediate-density lipoproteins, and LDL), and contributes to the development of atherosclerotic plaque [3], [10]. Subclinical atherosclerosis is defined as endothelial dysfunction, coronary calcification, and increased carotid intima-media thickness (cIMT) [11]. Increased cIMT and plaque formation are biologically and genetically distinct entities [12], [13]. A cIMT is a risk factor for cardiovascular events in addition to the other conventional vascular risk factors [13], [14]. Both calcified and non-calcified plaques are independent predictors of vascular disease for all age groups.

Increasing evidence supports a role for Vitamin $D$ that extends beyond that of bone health [15]. Vitamin D deficiency is a known risk factor for CVD [16]. Low Vitamin D level in a patient with T1D is associated with future development of microalbuminuria, retinopathy, and coronary artery calcification as well as increased risk of all-cause mortality [17]. In addition, 
Vitamin D deficiency has also been associated with the activation of the renin-angiotensin-aldosterone system and increased levels of inflammatory mediators resulting in target organ injury [18].

The balance between pro-inflammatory and anti-inflammatory cytokines is crucial in terms of both beta-pancreatic cell destruction and atherosclerotic plaque formation. Interferon- $\gamma$ (IFN- $\gamma$ ) and interleukin-17 (IL-17) are secreted by Th1 and Th17 subset, which associated with beta-cell destruction and pro-atherogenic, while IL-10 and transforming growth factor- $\beta 1$ (TGF- $\beta 1$ ) are anti-inflammatory cytokines which conversely inhibit beta-cell damage and plaque formation [19], [20]. Although some data are in favor of the role of Vitamin $D$ in subclinical atherosclerosis, the association has not been settled yet. We aimed to evaluate the relationship between Vitamin $D$ level and cIMT in patients with T1D through assessing the level of IFN- $\gamma$, IL-17, IL-10, and TGF- $\beta 1$.

\section{Subjects and Methods}

\section{Study design}

This study was designed as a cross-sectional, which aimed to investigate the association of Vitamin D status with the level of various cytokines (IFN- $\gamma, \mathrm{IL}-17$, IL-10, and TGF- $\beta 1$ ) and the marker for premature atherosclerosis (cIMT and flow-mediated dilatation [FMD]). The procedures conducted in this study have been approved by the Research Ethical Committee, Faculty of Medicine, Universitas Brawijaya (No. 400/214/k.3/302/2018). Research subjects were recruited using the consecutive sampling method, where each patient who met the inclusion criteria was included in the study from the period of January to July 2019 until the minimum sample size was achieved (40 subjects) based on the calculation of sample size as described in the literature [21]. All the children included in this study were subjected to general history taking, clinical, and laboratory assessment continued with specific examinations (cytokines and vitamin D level, cIMT, and FMD). This study was conducted at Policlinic of Pediatric Endocrinology, Saiful Anwar Hospital, Malang, Indonesia.

Inclusion criteria for the T1D group were defined as follows: has been diagnosed with T1D, aged 10-18 years old, and the parents/guardian allowed him/her to be involved in this study after being given an explanation (informed consent). Exclusion criteria were defined as follows: Systemic infections, liver disorders, impaired kidney function, malignancy, and anemia (hemoglobin levels $<11 \mathrm{~g} / \mathrm{dL}$, history of taking Vitamin D supplementation within the previous 3 weeks, amlodipine, valsartan, and statin treatment). For the control group, to rule out the diagnosis of T1D, we conducted a $\mathrm{GAD}_{65}$ assay. $\mathrm{GAD}_{65}$ assay was conducted by using an indirect enzyme-linked immunoabsorbent assay (ELISA) method, as previously described by literature [22]. Nutritional status was defined by plotting body mass index (BMI) into a standardized WHO chart for children aged 10-19 years old, then categorized as obese, overweight, normal, and underweight.

\section{Measurement of cytokines and 25(OH) $D_{3}$ \\ level}

The level of cytokines was measured by ELISA methods as instructed by the manufacturer (IFN- $\gamma$, IL-17, IL-10, and TGF- $\beta 1$; R\&D systems). The level of $25(\mathrm{OH}) \mathrm{D}_{3}$ was quantitatively measured by the ELISA kit produced by Cusabio (cat. CSB-E07900h). Briefly, after collecting $5 \mathrm{~mL}$ of whole blood within the EDTA-coated tube, the samples were then centrifuged for $2500 \mathrm{rpm}$ for 15 minutes at room temperature. The supernatant then removed by using Pasteur pipettes into a new tube. The plasma samples then stored at $-80^{\circ} \mathrm{C}$ to be analyzed together with the other samples.

ELISA method was performed after all the samples obtained. The reagents, standard dilutions, and samples were prepared at room temperature (RT). After adding $200 \mu \mathrm{L}$ of assay diluent to each well, 100 $\mu \mathrm{L}$ of standard, control, or sample were added into each well, covered with adhesive strip, then incubated at room temperature for two hours. Sequentially, $400 \mu \mathrm{L}$ of washing buffer was added into each well and aspirated. This washing process was repeated four times. A $100 \mu \mathrm{L}$ of antibodies were added into each well, then incubated at RT for 30 minutes. The washing process then repeated for four times, continued with the addition of $100 \mu \mathrm{L}$ of substrate solution and incubation period at RT for 30 minutes. Finally, $100 \mu \mathrm{L}$ of stop solution was added into each well. The optical density (OD) of each plate was measured by using ELISA reader at the wavelength of $450 \mathrm{~nm}$. The level of cytokines in each sample was derived from the standard curve. The procedure for $25(\mathrm{OH}) \mathrm{D}_{3}$ measurement is quite similar to the measurement of cytokines except the antibody were replaced by enzyme conjugate, and the OD was analyzed at the wavelength of $650 \mathrm{~nm}$.

\section{Measurement of cIMT}

Analysis of cIMT was performed as previously described in the literature [23]. Briefly, the diameter of the left and right common carotid arteries were obtained from the M-mode picture of echocardiographic analysis (Philip Type 50G). This procedure was performed by a cardiologist. The measurement of carotid intima-media thickness (cIMT) was taken only from common carotid arteries (without internal carotid and carotid bulb) since it was technically feasible to be done in pediatric subjects. The premature atherosclerotic plaque was defined as cIMT of more than $0.5 \mathrm{~mm}$. 


\section{Measurement of FMD}

FMD analysis was conducted to evaluate the function of the artery and has been done as previously described by the literature [24]. Briefly, the diameter of the brachial artery was measured while the position of the right arm was relaxed and supine so that the ultrasound examination is performed on the brachial artery $5-10 \mathrm{~cm}$ above the antecubital fossa. The cuff was inflated at supra systolic pressure (40-50 $\mathrm{mmHg}$ above systolic pressure) for $5 \mathrm{~min}$; then sequentially, the cuff was quickly deflated and cause rapid blood flow. Arterial diameter is measured up to 5 min after the cuff was deflated, and the highest width is determined. Baseline diameter was defined as the diameter of the artery before the stimulation using an inflated sphygmomanometer cuff. The percentage of FMD is determined using a standardized formula as follows: $F M D \%=$ (peak diameter - baseline diameter)/ baseline diameter. While the peak diameter is the largest diameter after reactive hyperemia or after the cuff is suddenly deflated before returning to the base diameter, measured up to the $5^{\text {th }} \mathrm{min}$ after reactive hyperemia.

\section{Statistical analysis}

Statistical analysis was performed using SPSS for Windows software version 24.0. Patient demographic data, which includes age, sex, BMI, and laboratory examination results, are displayed in descriptive data. IL-10 and cIMT data were tested for normality (to determine the distribution of normal data or not) with Kolmogorov-Smirnov and variance homogeneity tests (to find out the same data variant or not). For the comparison study, if the variables were normally distributed and homogeneous, then the independent t-test was used. However, if the variables were not normally distributed and were not homogeneous, the Mann-Whitney test was used. Meanwhile, to see the correlation between IFN$\gamma$, IL-17, IL-10, TGF- $\beta 1$ with cIMT, and FMD performed Pearson correlation test. A value of $p<0.05$ indicates a statistically significant difference.

\section{Results}

\section{Characteristics of research subjects}

During the study period, we enrolled 80 subjects consisting of 40 T1D patients and 40 healthy control. Briefly, there were no significant differences between diabetic and control groups based on age, gender, complete blood count parameters, renal function test, and C-reactive protein (CRP) level ( $p>0.05$ ). Moreover, the $\mathrm{HbA} 1 \mathrm{c}$ level was significantly higher in the diabetic group compared with the control group ( $p<0.001)$. Furthermore, lipid assay panels showed that the T1D group had a significantly higher
LDL and total cholesterol level as compared to healthy subjects, but no difference was found in the TG and HDL levels. The characteristics of the subjects of this study are presented in Table 1.

Table 1: Characteristics of research subjects

\begin{tabular}{|c|c|c|c|}
\hline Characteristic & T1 diabetes $(n=40)$ & Control $(n=40)$ & $\mathrm{p}$-value \\
\hline Age (years) & $14.62 \pm 2.85$ & $14.6 \pm 0.98$ & 0.236 \\
\hline Duration of diabetes (year) & $4.75 \pm 1.33$ & - & \\
\hline \multicolumn{4}{|l|}{ Gender } \\
\hline Male & $17(43 \%)$ & $14(35 \%)$ & 0.453 \\
\hline Female & $23(57 \%)$ & $26(65 \%)$ & 0.542 \\
\hline Hemoglobin (g/dL) & $14.15 \pm 1.11$ & $14.57 \pm 1.83$ & 0.128 \\
\hline Leucocyte $\left(10^{3}\right.$ cells/ųL) & $8.484 \pm 2.789$ & $7.529 \pm 1.337$ & 0.149 \\
\hline Thrombocyte $\left(10^{3}\right.$ cells/ųL) & $362.92 \pm 62.49$ & $346.12 \pm 86.05$ & 0.341 \\
\hline Urea $(\mathrm{mg} / \mathrm{dL})$ & $23 \pm 12$ & $19.88 \pm 5.2$ & 0.315 \\
\hline Creatinine (mg/dL) & $0.6 \pm 0.4$ & $0.64 \pm 0.15$ & 0.057 \\
\hline C-reactive protein (mg/dL) & $0.14 \pm 0.14$ & $0.11 \pm 0.22$ & 0.056 \\
\hline \multicolumn{4}{|l|}{ Nutritional status } \\
\hline Normal & $29(72 \%)$ & $34(85 \%)$ & \\
\hline Underweight & $7(18 \%)$ & $2(5 \%)$ & \\
\hline Overweight & $4(10 \%)$ & $4(10 \%)$ & \\
\hline HbA1c (\%) & $9.55 \pm 2.02$ & $4.72 \pm 0.24$ & $<0.001^{*}$ \\
\hline$<6.5 \%$ & $3(8 \%)$ & $40(100 \%)$ & \\
\hline$\geq 6.5 \%$ & $37(92 \%)$ & 0 & \\
\hline Triglycerides (mg/dl) & $107.5 \pm 42.7$ & $95.2 \pm 45.01$ & 0.087 \\
\hline Normal $<90$ mg/dl & $38(95 \%)$ & $36(90 \%)$ & \\
\hline High >150 mg/dl & $2(5 \%)$ & $4(10 \%)$ & \\
\hline Total cholesterol (mg/dl) & $173.9 \pm 36.8$ & $132.5 \pm 29.4$ & $<0.001^{*}$ \\
\hline Normal $<200$ mg/dl & $39(98 \%)$ & $39(98 \%)$ & \\
\hline High >240 mg/dl & $1(2 \%)$ & $1(2 \%)$ & \\
\hline LDL (mg/dl) & $127 \pm 32$ & $90.18 \pm 25.34$ & $<0.001^{*}$ \\
\hline Normal <100 mg/dl & $33(85 \%)$ & $40(100 \%)$ & \\
\hline High >160 mg/dl & $6(15 \%)$ & 0 & \\
\hline $\mathrm{HDL}(\mathrm{mg} / \mathrm{dl})$ & $56.3 \pm 14.5$ & $51.48 \pm 10.78$ & 0.100 \\
\hline Low <40 mg/dl & $27(68 \%)$ & $37(93 \%)$ & \\
\hline High $>60 \mathrm{mg} / \mathrm{dl}$ & $13(32 \%)$ & $3(7 \%)$ & \\
\hline
\end{tabular}

\section{Comparison of $25(\mathrm{OH}) \mathrm{D}_{3}$, premature} atherosclerotic marker, and cytokines levels

Our data demonstrated that the level of $25(\mathrm{OH}) \mathrm{D}_{3}$ in children with T1D was significantly lower as compared to the control group $(p<0.001)$. Furthermore, while the level of pro-inflammatory cytokines (IL-17 and IFN- $\gamma$ ) was significantly elevated in the T1D group compared to the control group ( $p<0.05)$, the level of anti-inflammatory cytokines were significantly reduced in T1D group compared with the control group ( $p<0.001)$. The cIMT value in the T1D group was significantly higher compared to the control group ( $p<0.001)$, suggesting that children with T1D have a higher susceptibility to develop CVD. In agreement with the structural defect as determined by cIMT, children with T1D have an impaired arterial function reflected by significantly lower FMD value compared to the control group ( $p<0.001)$. The detail of these comparisons is presented in Table 2.

Table 2: Comparison of the level of Vitamin D, cytokines, cIMT, and FMD

\begin{tabular}{|c|c|c|c|}
\hline Variable & T1 diabetes $(n=40)$ & Control $(n=40)$ & $p$-value \\
\hline Vitamin D $\left(25[\mathrm{OH}] \mathrm{D}_{3}\right)$ & $10.41 \pm 2.24$ & $18.04 \pm 1.41$ & $<0.001^{*}$ \\
\hline Deficiency $(<20 \mathrm{ng} / \mathrm{ml})$ & $37(93 \%)$ & $38(95 \%)$ & \\
\hline Insufficiency $(20-30 \mathrm{ng} / \mathrm{ml})$ & $3(7 \%)$ & $2(5 \%)$ & \\
\hline Sufficiency (>30 ng/ml) & 0 & 0 & \\
\hline \multicolumn{4}{|l|}{ Cytokines levels } \\
\hline TGF- $\beta 1$ (pg/mL) & $39.83 \pm 13.51$ & $73.6 \pm 15.34$ & $<0.001^{*}$ \\
\hline $\mathrm{IL}-10(\mathrm{pg} / \mathrm{mL})$ & $3.19 \pm 0.85$ & $9.39 \pm 1.07$ & $<0.001^{*}$ \\
\hline $\mathrm{IL}-17$ (pg/mL) & $4.89 \pm 1.86$ & $3.30 \pm 0.56$ & $<0.001^{*}$ \\
\hline IFN-y (pg/mL) & $26.06 \pm 16.65$ & $16.74 \pm 7.20$ & $0.001^{*}$ \\
\hline \multicolumn{4}{|l|}{ Atherosclerotic marker } \\
\hline $\mathrm{clMT}(\mathrm{mm})$ & $0.567 \pm 0.87$ & $0.387 \pm 0.57$ & $<0.001^{*}$ \\
\hline FMD (\%) & $7.17 \pm 3.98$ & $11.22 \pm 5.48$ & $<0.001^{*}$ \\
\hline Baseline diameter (mm) & $2.86 \pm 0.46$ & $3.07 \pm 0.44$ & $<0.001^{*}$ \\
\hline Peak diameter $(\mathrm{mm})$ & $3.18 \pm 0.46$ & $3.65 \pm 0.51$ & $<0.001^{*}$ \\
\hline
\end{tabular}




\section{Correlation between 25(OH) $D_{3}$ level and the cytokines level}

To examine whether the Vitamin D status is associated with the balance between proinflammatory and anti-inflammatory markers, we performed a correlation analysis. Our data revealed that the $25(\mathrm{OH}) \mathrm{D}_{3}$ level was positively associated with anti-inflammatory cytokines (IL-10 and TGF- $\beta 1$ ). On the other hand, the $25(\mathrm{OH}) \mathrm{D}_{3}$ level was negatively correlated with pro-inflammatory cytokine (IL-17 and IFN- $\gamma$ ). This result indicates that Vitamin $\mathrm{D}$ modulates the inflammatory response through the attenuation of pro-inflammatory processes. The results of correlation analysis between vitamin $D$ and cytokine levels is presented in Table 3.

Table 3: Correlation cytokines and Vitamin D level in type 1 diabetes patients

\begin{tabular}{lll}
\hline Cytokine & $r$ & $p$ \\
\hline IFN- $\gamma$ & -0.795 & $<0.001$ \\
IL-17 & -0.797 & $<0.001$ \\
IL-10 & 0.822 & $<0.001$ \\
TGF- $\beta 1$ & 0.746 & $<0.001$ \\
\hline TGF- $\beta 1$ : Transforming growth factor- $\beta 1$, IFN- - I Interferon- - , IL: Interleukin. &
\end{tabular}

\section{cIMT}

\section{Correlation between cytokines level and}

To determine the association between atherosclerotic plaque formation and inflammatory processes, we conducted a correlation analysis. Our data demonstrated that cIMT is negatively correlated with IL-10 level $(p<0.001, r=-0.629)$ and TGF- $\beta 1$ level ( $p<0.001, r=-0.547)$. On the other hand, clMT was positively correlated with IL-17 level $(p<0.001, r=0.569)$ and IFN- $\gamma$ level $(p<0.001, r=0.650)$. These data suggest that the development of atherosclerosis plaque, particularly in the carotid arteries, is strongly associated with the inflammatory response. The graph presented the correlation between cytokine levels and cIMT value is shown in Figure 1.

\section{Correlation between cytokines level and}

\section{FMD}

To investigate the association between inflammatory response and the function of the carotid artery, we performed a correlation study. Our data demonstrated that FMD was positively correlated with IL-10 level ( $p<0.001, r=0.635)$ and TGF- $\beta 1$ level $(p<0.001, r=0.592)$. On the other hand, FMD was negatively correlated with IL-17 level $(p<0.001, r=-0.640)$ and IFN- $\gamma$ level $(p<0.001$, $r=-0.655)$. Taken together with the cIMT data, these results indicate that pro-inflammatory cytokines have a positive impact on the stiffness of the artery, thus decreasing the FMD. The graph presented the correlation between cytokine levels and FMD value is shown in Figure 2.

\section{The relationship between T1D and} premature atherosclerosis

Based on the Chi-square test, there was a significant relationship between the incidence of T1D with the incidence of atherosclerosis based on clMT value $(\mathrm{OR}=37,000 ; 95 \% \mathrm{Cl}=9.3-146.6)$, indicating that patient with T1D has 37-fold higher risk to develop premature atherosclerosis compared to healthy control. The association analysis of type 1 diabetes and premature atherosclerosis is shown in Table 4.

Table 4: The relationship between type 1 diabetes and premature atherosclerosis

\begin{tabular}{llllll}
\hline Group & \multicolumn{2}{l}{ Carotid intima-media thickness } & Total & p-value \\
\cline { 2 - 3 } & $<0.5 \mathrm{~mm}$ (negative) & $>0.5 \mathrm{~mm}$ (positive) & & \\
\hline Control & 37 & 3 & 40 & $<0.001$ \\
Type 1 diabetes & 10 & 30 & 40 & \\
Total & 57 & 40 & 80 & \\
OR=37.000 & & $\mathrm{Cl} \mathrm{95 \% =9.335-146.651}$ & & \\
\hline
\end{tabular}

\section{Predictor variables of premature atherosclerosis}

To investigate the predictor variables for the development of premature atherosclerosis, we performed logistic regression analysis on gender, age, duration of diabetes mellitus, lipid profile, $\mathrm{HbA1c}$ level, BMI, cytokines level, and $25(\mathrm{OH}) \mathrm{D}_{3}$ level. Interestingly, a preliminary correlation study showed that gender, age, duration of diabetes mellitus, lipid profile, $\mathrm{HbA} 1 \mathrm{c}$ level, and BMI did not significantly correlate with premature atherosclerosis $(p>0.05)$ (Table 5). However, the level of $25(\mathrm{OH}) \mathrm{D}_{3}$ is significantly correlated with cIMT value $(p<0.001)$.

Table 5: Correlation of subject characteristics and premature atherosclerosis

\begin{tabular}{lll}
\hline Correlation & $\mathrm{p}$ & $\mathrm{r}$ \\
\hline CIMT and age & 0.106 & -0.260 \\
CIMT and duration of DM & 0.124 & -0.247 \\
CIMT and gender & 0.653 & -0.073 \\
CIMT and BMI & 0.890 & 0.023 \\
CIMT and HbA1c & 0.686 & -0.066 \\
CIMT and total cholesterol level & 0.508 & 0.108 \\
CIMT and LDL level & 0.847 & 0.032 \\
CIMT and HDL level & 0.246 & 0.188 \\
CIMT and TG level & 0.658 & -0.072 \\
CIMT and 25(OH) $D_{3}$ level & $<0.001$ & 0.853 \\
\hline cIMT: Carotid intima-media thickness, BMI: Body mass index, HDL: High-density lipoprotein, LDL: Low- \\
density lipoprotein, TG: Triglyceride, DM: Diabetes mellitus.
\end{tabular}

Other variables, such as cytokines level (IL-17, IFN- $\gamma$, IL-10, and TGF- $\beta 1$ ) and $25(\mathrm{OH}) \mathrm{D}_{3}$, were significantly correlated with premature atherosclerosis $(p<0.001)$. Surprisingly, logistic regression analysis by including the cytokines and $25(\mathrm{OH}) \mathrm{D}_{3}$ levels showed that these variables did not significantly influence premature atherosclerosis (Table 6).

Table 6: Predictor variables for premature atherosclerosis

\begin{tabular}{lllllll}
\hline Variables & $\mathrm{B}$ & $\mathrm{SE}$ & Wald & $\mathrm{p}$ & $\mathrm{OR}$ & $95 \% \mathrm{Cl}$ \\
\hline $25(\mathrm{OH}) \mathrm{D}_{3}$ & 0.863 & 1.377 & 0.393 & 0.531 & 2.370 & $0.2-35.2$ \\
IFN- $\gamma$ & 1.533 & 0.962 & 2.537 & 0.111 & 4.631 & $0.7-30.5$ \\
IL-10 & -0.218 & 1.307 & 0.028 & 0.868 & 0.804 & $0.1-10.4$ \\
IL-17 & 0.959 & 1.631 & 0.346 & 0.556 & 2.610 & $0.1-63.8$ \\
TGF- $\beta 1$ & 0.120 & 0.122 & 0.957 & 0.328 & 1.127 & $0.9-1.4$ \\
Constant & -56.1 & 26.5 & 4.5 & 0.034 & 0.000 & \\
\hline \multicolumn{7}{l}{ IFN- $\gamma$ : Interferon- - I IL: Interleukin, TGF- $\beta 1$ : Transforming growth factor- $\beta 1}$.
\end{tabular}




\section{Receiver operating characteristic (ROC)} analysis on the $25(\mathrm{OH}) \mathrm{D}_{3}$ level and premature atherosclerosis

ROC curve shows that the cutoff value for $25(\mathrm{OH}) \mathrm{D}_{3}$ levels for the risk factor of premature atherosclerosis is $12.80 \mathrm{ng} / \mathrm{dL}$. Based on the cutoff value, $25(\mathrm{OH}) \mathrm{D}_{3} \leq 12.80 \mathrm{ng} / \mathrm{dL}$ is categorized as a higher risk for the development or progression of premature atherosclerosis (sensitivity $85.7 \%$, specificity $86.7 \%$, accuracy $86.3 \%, p<0.001)$. The result of ROC analysis is shown in Figure 3.

\section{Discussion}

Our data demonstrated that the T1D group had a significantly higher level of LDL and total cholesterol, but no differences were found in the TG and HDL values. Quantitative lipoprotein abnormalities could be found in T1D patients with poor glycemic control (elevated plasma triglycerides and LDL cholesterol) or nephropathy (elevated triglycerides and LDL cholesterol, high-density lipoprotein levels). T1D with optimal glycemic control, plasma triglycerides, and LDL cholesterol are normal or slightly decreased, whereas HDL cholesterol is normal or slightly increased. Several qualitative abnormalities of lipoprotein, which are potentially atherogenic, were observed in patients with T1D, even with good metabolic control [25], [26].

The current study suggests that patients with T1D mellitus have significantly reduced Vitamin D levels, higher pro-inflammatory activity, and lower anti-inflammatory activity. These factors are possibly contributing to carotid stiffness and plaque deposition, as represented by elevated cIMT and reduced FMD. Correlation study also supports the notion that Vitamin D deficiency is strongly associated with the imbalance between pro-inflammatory and anti-inflammatory activity. Consequently, the profound activation of pro-inflammatory cells contributes to the development of atherosclerotic plaque.

In the diabetic state, a chronic inflammatory process is well-known as an important risk factor for $\beta$ cell damage, insulin resistance, and diabetic
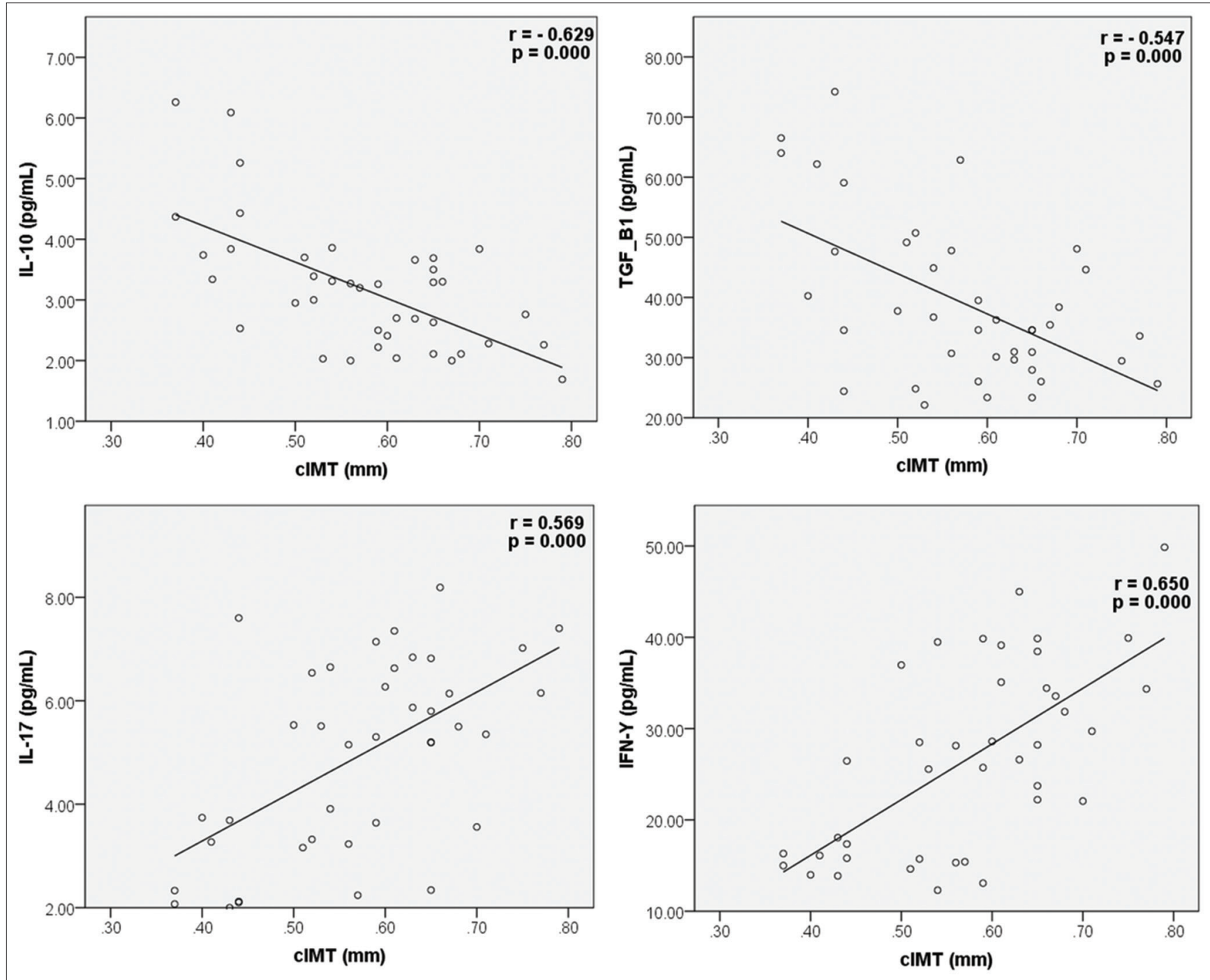

Figure 1: Correlation between carotid intima-media thickness and pro-inflammatory or anti-inflammatory cytokines. 

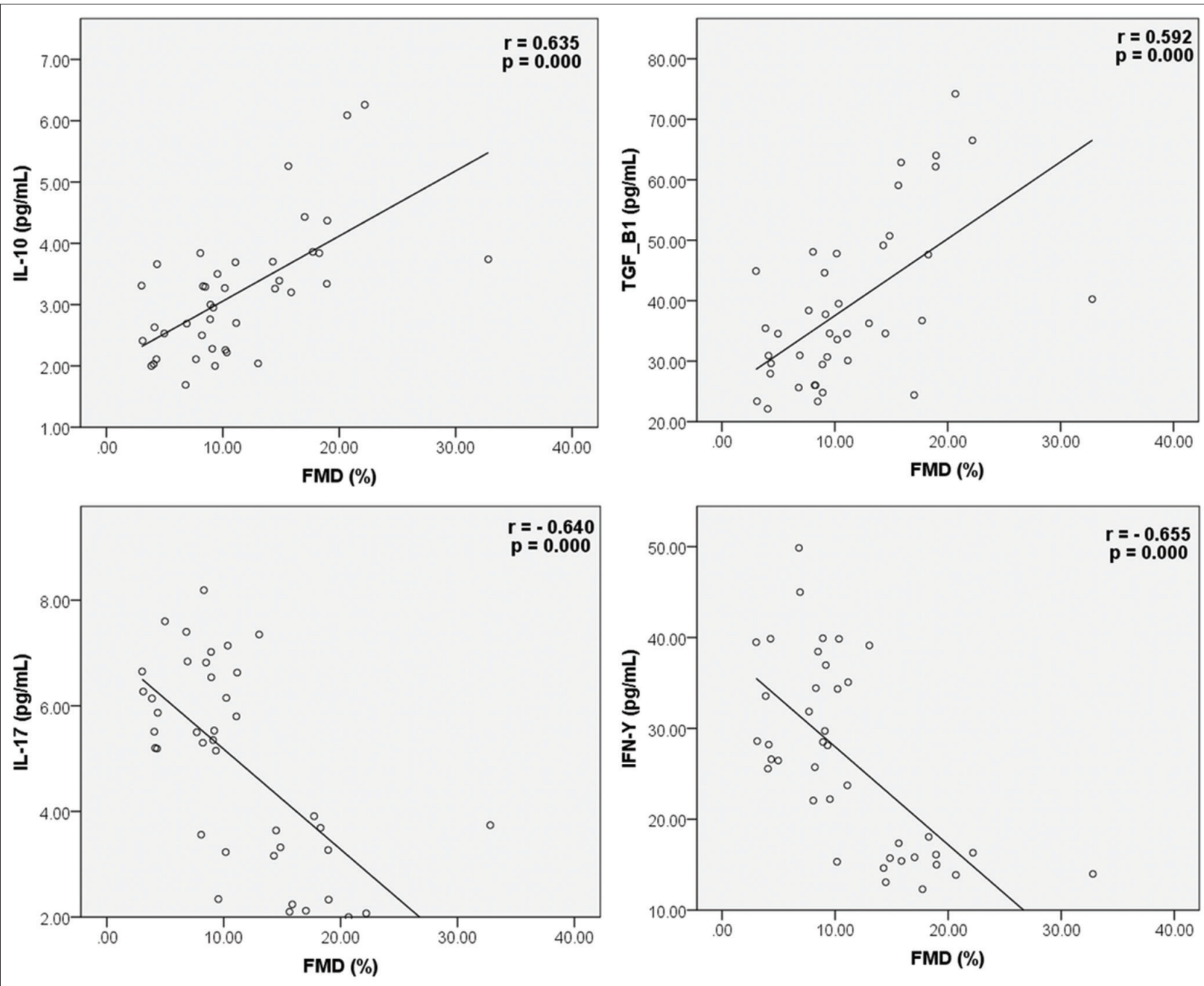

Figure 2: Correlation between flow-mediated dilatation and pro-inflammatory or anti-inflammatory cytokines

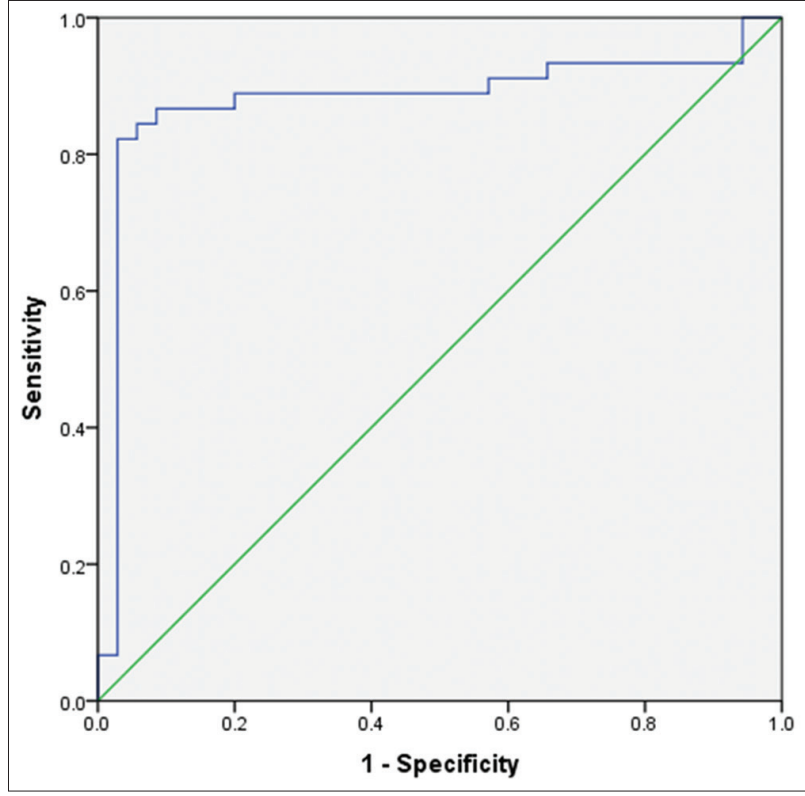

Figure 3: Receiver operating characteristic analysis on $25(\mathrm{OH}) \mathrm{D}_{3}$ level and the development of premature atherosclerosis

vascular complications, endothelial dysfunction, and procoagulant imbalance [27], [28], [29]. An observational study demonstrated that T1D is an independent risk factor for increased carotid IMT in children [30], [31]. Inflammatory processes occur in atherosclerotic conditions characterized by increased CRP, pro-inflammatory cytokines, and decreased anti-inflammatory cytokines. The levels of hs-CRP, IL-6, IL-10 are independently related to the level of atherosclerosis [8], [32]. On the other hand, higher serum IL-10 levels are associated with a long-term risk of cardiovascular events [33].

Atherosclerosis is a chronic inflammatory disease of the arterial wall driven by innate and adaptive immune responses. Inflammation controls the development and the destabilization of arterial plaque. Cells involved in the atherosclerotic process secrete and are activated by soluble factors, known as cytokines. Important recent advances in the comprehension of the mechanisms of atherosclerosis have provided evidence for a dual role of cytokines: Pro-inflammatory and $\mathrm{T}$ helper-1-related cytokines promote the development and progression of the disease, whereas anti-inflammatory and regulatory $\mathrm{T}$ cell-related cytokines exert clear antiatherogenic activities [34], [35], [36]. 
Recent studies showed that several pro-atherogenic factors, including cholesterol, oxidized LDL, and fatty acids, regulate the production of IL-17 and IL-17-promoting cytokines from innate and adaptive immune cells. Given that IL-17 is associated with a number of autoimmune diseases in humans, dissecting the mechanisms beyond the mutual regulation of pro-atherogenic factors and IL-17 might provide a novel pathophysiology between atherosclerosis and autoimmune diseases [37], [38]. The mechanism of protection appeared to be related to overt decreases in inflammation as levels of serum cytokines such as IL-6, IFN- $\gamma$, and IL-12 were reduced into the inflammatory process in atherosclerosis [39].

Vitamin D deficiency is related to enhance pro-inflammatory or autoimmune activity and atherosclerosis formation in T1D patients [40]. Low 25-hydroxyvitamin D levels were associated with increased intima-media thickness and maximal carotid plaque thickness in those with plaque, and 25-hydroxyvitamin $D$ contributed in a robust manner to the variance in both. These results confirm and extend data on the association of low Vitamin $D$ levels with subclinical carotid atherosclerosis [41], [42], [43], [44]. In addition, in advanced disease, there was a significant negative correlation between $25(\mathrm{OH}) \mathrm{D}$ and $\mathrm{IL}-17$ in the diabetic neuropathy groups, suggesting that Vitamin $\mathrm{D}$ is a potentially modifiable risk factor for diabetes and may regulate inflammatory mediators, for example, IL-17 and IL-13 [45]. Clinically, Vitamin D levels were associated with $\mathrm{HbA} 1 \mathrm{c}$ levels and IL-10 levels in T1DM [46]. An animal study also showed that 1,25$(\mathrm{OH})_{2} \mathrm{D}_{3}$ had a partially protective effect on diabetic rats, which might be through the inhibition of growth factors, VEGF, and TGF- $\beta_{1}$ [47].

IL-10 plays a role in cardiac remodeling and has a protective effect on autoimmune diseases, one of which is T1D. In the process of atherosclerosis, IL-10 can be both an agent that causes atherosclerosis and an atheroprotective agent [28], [29]. The functions of IL-10 are to control cell proliferation, cell migration, matrix synthesis, wound contraction, calcification, and immune response and all are major components of the atherosclerotic process. However, many of the effects of IL-10 are important for tissue repair; hence, IL-10 is also considered atheroprotective. The role of IL-10 in blood vessels is to inhibit the proliferation of endothelial and smooth muscle of blood vessels and play a role in tissue repair. Clinically, lower levels of IL-10 are correlated with atherosclerosis [48]. As the cIMT represents atherosclerosis, whereas IL-10 acts as an anti-atherosclerosis agent, the IL-10 level would be negatively correlated with cIMT [34], [49], [50]. In agreement with the previous studies, our data showed the same finding. Furthermore, our study showed that the TGF- $\beta 1$ level was also negatively associated with cIMT. Conversely, a previous study demonstrated that elevated TGF- $\beta$ levels in diabetes play a pathogenic role in the development of accelerated atherosclerosis in diabetes. Consequently, blocking growth factor actions on proteoglycan synthesis with many known cardiovascular and diabetes drugs attenuates lipid binding and potentially provides pleiotropic activities that assist in the prevention of atherosclerosis [51].

Our study showed important data regarding the relation of anti-inflammatory and pro-inflammatory cytokines and the development of premature atherosclerosis in children with type 1 diabetes. Nonetheless, because the current study was designed as a cross-sectional, it has less capability to explain the causative role of cytokine levels and plaque deposition. A prospective cohort might be required to address this highlighted issue. Furthermore, although the sample size has been fulfilled the minimum requirement for the statistical analysis, obtaining more subjects, or recruiting the subjects from different age groups might be beneficial to improve its clinical applicability.

\section{Conclusions}

We concluded that low Vitamin $D$ levels are associated with premature atherosclerosis as determined by the elevation of intima-media thickness and the reduction of FMD of the common carotid artery. The pathogenesis of how Vitamin D affects the development of atherosclerosis might be related to the imbalance between pro-inflammatory (IL-17 and IFN- $\Upsilon$ ) and anti-inflammatory (TGF- $\beta 1$ and IL-10) cytokines. Our data also suggests that T1D patient with Vitamin D level $\leq 12.80 \mathrm{ng} / \mathrm{dL}$ has a higher risk for the development of premature atherosclerosis.

\section{References}

1. International Diabetes Foundation. Diabetes atlas. $6^{\text {th }}$ ed. Vol. 6 . International Diabetes Foundation; 2017. p. 142-5.

2. Kemenkes Republik Indonesia. Hasil Utama Riset Kesehatan Dasar Tahun. Indonesia: Kementrian Kesehatan Republik Indonesia; 2018. https://doi.org/10.6066/jtip.2013.24.2.121

3. Hoffman RP. Vascular endothelial dysfunction and nutritional compounds in early Type 1 diabetes. Curr Diabetes Rev 2014;10(3):201-7. https://doi.org/10.2174/15733998106661406 13124326

PMid:24925525

4. Lee SI, Patel M, Jones CM, Narendran P. Cardiovascular disease and Type 1 diabetes: Prevalence, prediction and management in an ageing population. Ther Adv Chronic Dis 2015;6(6):347-74.

PMid:26568811

5. Krantz JS, Mack WJ, Hodis HN, Liu CR, Kaufman FR. Early onset of subclinical atherosclerosis in young persons with Type 1 diabetes. J Pediatr 2004;145(4):452-7. https://doi.org/10.1016/j. 
jpeds.2004.06.042

PMid: 15480366

6. Purnell JQ, Zinman B, Brunzell JD; DCCT/EDIC Research Group. The effect of excess weight gain with intensive diabetes mellitus treatment on cardiovascular disease risk factors and atherosclerosis in Type 1 diabetes mellitus: Results from the diabetes control and complications trial/epidemiology of diabetes interventions and complications study (DCCT/EDIC) study. Circulation 2013;127(2):180-7. https://doi.org/10.1161/ circulationaha.111.077487

PMid:23212717

7. Muis MJ, Bots ML, Bilo HJ, Hoogma RP, Hoekstra JB, Grobbee DE, et al. High cumulative insulin exposure: A risk factor of atherosclerosis in Type 1 diabetes? Atherosclerosis 2005;181(1):185-92. https://doi.org/10.1016/j. atherosclerosis.2005.01.004

PMid:15939071

8. Dahl-Jørgensen K, Larsen JR, Hanssen KF. Atherosclerosis in childhood and adolescent Type 1 diabetes: Early disease, early treatment? Diabetologia 2005;48(8):1445-53. https://doi. org/10.1007/s00125-005-1832-1

PMid:15971059

9. Hernández M, López $C$, Real J, Valls J, de Victoria EO, Vazquez $\mathrm{F}$, et al. Preclinical carotid atherosclerosis in patients with latent autoimmune diabetes in adults (LADA), Type 2 diabetes and classical type 1 diabetes. Cardiovasc Diabetol 2017;16(1):94. https://doi.org/10.1186/s12933-017-0576-9 PMid:28750634

10. Frismantiene A, Pfaff D, Frachet A, Coen M, Joshi MB, Maslova K, et al. Regulation of contractile signaling and matrix remodeling by T-cadherin in vascular smooth muscle cells: Constitutive and insulin-dependent effects. Cell Signal 2014;26(9):1897-908. https://doi.org/10.1016/j.cellsig.2014.05.001

PMid:24815187

11. Bauer M, Caviezel S, Teynor A, Erbel R, Mahabadi A, SchmidtTrucksass A. Carotid intima-media thickness as a biomarker of subclinical atherosclerosis. Swiss Med Wkly 2012;142:w13705. https://doi.org/10.4414/smw.2012.13705

PMid:23135891

12. Bartels $S$, Franco AR, Rundek T. Carotid intima-media thickness (cIMT) and plaque from risk assessment and clinical use to genetic discoveries. Perspect Med 2012;1(1-12):139-45. https:// doi.org/10.1016/j.permed.2012.01.006

13. Den Ruijter HM, Peters SA, Anderson TJ, Britton AR, Dekker JM, Eijkemans MJ, et al. Common carotid intima-media thickness measurements in cardiovascular risk prediction: A metaanalysis. JAMA 2012;308(8):796-803. https://doi.org/10.1016/j. jvs.2012.10.058

\section{PMid:22910757}

14. Simon A, Megnien JL, Chironi G. The value of carotid intimamedia thickness for predicting cardiovascular risk. Arterioscler Thromb Vasc Biol 2010;30(2):182-5. https://doi.org/10.1161/ atvbaha.109.196980

PMid:19948842

15. Norman PE, Powell JT. Vitamin D and cardiovascular disease. Circulation Res 2014;114(2):379-93.

PMid:22689009

16. Apostolakis M, Armeni E, Bakas P, Lambrinoudaki I. Vitamin D and cardiovascular disease. Maturitas 2018;115:1-22. https:// doi.org/10.1016/j.maturitas.2018.05.010

PMid:30049340

17. van Schoor NM, Lips P. Worldwide Vitamin D status. Best Pract Res Clin Endocrinol Metab 2011;25(4):671-80.

PMid:21872807
18. Santoro D, Caccamo D, Lucisano S. Interplay of Vitamin D, erythropoiesis, and the renin-angiotensin system. Biomed Res Int 2015;2015:145828. https://doi.org/10.1155/2015/145828 PMid:26000281

19. DiMeglio LA, Evans-Molina C, Oram RA. Type 1 diabetes. Lancet 2018;391(10138):2449-62. https://doi.org/10.1016/ s0140-6736(18)31320-5 PMid:29916386

20. Taleb S, Tedgui A, Mallat Z. IL-17 and Th17 cells in atherosclerosis: Subtle and contextual roles. Arterioscler Thromb Vasc Biol 2015;35(2):258-64. https://doi.org/10.1161/ atvbaha.114.303567

PMid:25234818

21. McLaren JE, Ramji DP. Interferon gamma: a master regulator of atherosclerosis. Cytokine Growth Factor Rrev. 2009;20(2):12535. http://doi.org/10.1016/j.cytogfr.2008.11.003 PMid: 19041276

22. Delic-Sarac M, Mutevelic S, Karamethic J, Subasic D, Jukic T, Ridjic $O$, et al. ELISA test for analyzing of incidence of type 1 diabetes autoantibodies (GAD and IA2) in children and adolescents. Acta Inform Med 2016;24(1):61-5. https://doi. org/10.5455/aim.2016.24.61-65

PMid:27041813

23. Chen LJ, Lim SH, Yeh YT, Lien SC, Chiu JJ. Roles of microRNAs in atherosclerosis and restenosis. J Biomed Sci.2012;19(1):79. https://doi.org/10.1186/1423-0127-19-79 PMid:22931291

24. Toma I, McCaffrey TA. Transforming growth factor- $\beta$ and atherosclerosis: Interwoven atherogenic and atheroprotective aspects. Cell Tissue Res. 2012;347(1):155-75. https://doi. org/10.1007/s00441-011-1189-3

\section{PMid:21626289}

25. Hoving LR, Katiraei S, Heijink M, Pronk A, van der Wee-Pals L, Streefland $\mathrm{T}$, et al. Dietary mannan oligosaccharides modulate gut microbiota, increase fecal bile acid excretion, and decrease plasma cholesterol and atherosclerosis development. Mol Nutr Food Res 2018;62(10):e1700942. https://doi.org/10.1002/ mnfr.201700942

PMid:29665623

26. Taylor AJ, Sullenberger LE, Lee HJ, Lee JK, Grace KA. Arteria biology for the investigation of the treatment effects of reducing cholesterol (ARBITER) 2: A double-blind, placebo-controlled study of extended-release niacin on atherosclerosis progression in secondary prevention patients treated with statins. Circulation 2004;110(23):3512-7. https://doi.org/10.1161/01. cir.0000148955.19792.8d

PMid: 15537681

27. Cabrera SM, Henschel AM, Hessner MJ. Innate inflammation in Type 1 diabetes. Transl Res 2016;167(1):214-27. https://doi. org/10.1016/j.trsl.2015.04.011 PMid:25980926

28. Bijjiga E, Martino A. Interleukin 10 (IL-10) regulatory cytokine and its clinical consequences. J Clin Cell Immunol 2013;S1:7. https://doi.org/10.4172/2155-9899.s1-007

29. Cutolo M, Paolino S, Sulli A, Smith V, Pizzorni C, Seriolo B. Vitamin D, steroid hormones, and autoimmunity. Ann N Y Acad Sci 2014;1317:39-46. https://doi.org/10.1111/nyas.12432 PMid:24739090

30. Ammirati E, Moroni F, Norata GD, Magnoni M, Camici PG. Markers of inflammation associated with plaque progression and instability in patients with carotid atherosclerosis. Mediators Inflamm 2015;2015:718329. https://doi. org/10.1155/2015/718329

PMid:25960621 
31. Atwa HA, Shora HA, Elsayed A. Hormonal, metabolic and radiological markers of subclinical atherosclerosis in Egyptian children with Type 1 diabetes. Rep Endocr Disord 2018;2(1):3.

32. Trigona B, Aggoun Y, Maggio A, Martin XE, Marchand LM, Beghetti $M$, et al. Preclinical noninvasive markers of atherosclerosis in children and adolescents with Type 1 diabetes are influenced by physical activity. J Pediatr 2010;157(4):533-9. https://doi.org/10.1016/j.jpeds.2010.04.023

\section{PMid:20826281}

33. Kamaly N, Fredman G, Fojas JJ, Subramanian M, Choi WI Zepeda $\mathrm{K}$, et al. Targeted interleukin-10 nanotherapeutics developed with a microfluidic chip enhance resolution of inflammation in advanced atherosclerosis. ACS Nano 2016;10(5):5280-92. https://doi.org/10.1021/acsnano.6b01114 PMid:27100066

34. Ait-Oufella H, Taleb S, Mallat Z, Tedgui A. Recent advances on the role of cytokines in atherosclerosis. Arterioscler Thromb Vasc Biol 2011;31(5):969-79. https://doi.org/10.1161/ atvbaha.110.207415 PMid:21508343

35. Tedgui A, Mallat Z. Cytokines in atherosclerosis: Pathogenic and regulatory pathways. Physiol Rev 2006;86(2):515-81. https://doi.org/10.1152/physrev.00024.2005 PMid:16601268

36. Ross R. Atherosclerosis an inflammatory disease. N Eng J Med 1999;340(2):115-26. PMid:22390643

37. Ryu H, Chung Y. Regulation of $\mathrm{IL}-17$ in atherosclerosis and related autoimmunity. Cytokine 2015;74(2):219-27. https://doi. org/10.1016/j.cyto.2015.03.009 PMid:25890878

38. Allam G, Abdel-Moneim A, Gaber AM. The pleiotropic role of interleukin-17 in atherosclerosis. Biomed Pharmacother 2018;106:1412-18. https://doi.org/10.1016/j.biopha.2018.07.110 PMid:30119214

39. Major AS, Harrison DG. What fans the fire: Insights into mechanisms of inflammation in atherosclerosis and diabetes mellitus. Circulation 2011;124(25):280911. https://doi. org/10.1161/circulationaha.111.070565 PMid:22184043

40. Tiwari S, Pratyush DD, Gupta SK, Singh SK. Vitamin D deficiency is associated with inflammatory cytokine concentrations in patients with diabetic foot infection. Br J Nutr 2014;112(12):193843. https://doi.org/10.1017/s0007114514003018 PMid:25331710

41. Carrelli AL, Walker MD, Lowe H, McMahon DJ, Rundek T, Sacco RL, et al. Vitamin $\mathrm{D}$ deficiency is associated with subclinical carotid atherosclerosis: The Northern Manhattan study. Stroke 2011;42(8):2240-5. https://doi.org/10.1161/ strokeaha.110.608539

PMid:21719770
42. Devaraj S, Yun JM, Duncan-Staley CR, Jialal I. Low Vitamin D levels correlate with the proinflammatory state in Type 1 diabetic subjects with and without microvascular complications. Am J Clin Pathol 2011;135(3):429-33. https://doi.org/10.1309/ ajcpjgzqx42biaxl PMid:21350098

43. Young KA, Snell-Bergeon JK, Naik RG, Hokanson JE, Tarullo D, Gottlieb PA, et al. Vitamin D deficiency and coronary artery calcification in subjects with Type 1 diabetes. Diabetes Care 2011;34(2):454-8. https://doi.org/10.2337/dc10-0757 PMid:20978098

44. Sachs MC, Brunzell JD, Cleary PA, Hoofnagle AN, Lachin JM, Molitch ME, et al. Circulating Vitamin D metabolites and subclinical atherosclerosis in Type 1 diabetes. Diabetes Care 2013;36(8):2423-9. https://doi.org/10.2337/dc12-2020 PMid:23530012

45. Bilir B, Tulubas F, Bilir BE, Atile NS, Kara SP, Yildirim T, et al. The association of Vitamin $D$ with inflammatory cytokines in diabetic peripheral neuropathy. J Phys Ther Sci 2016;28(7):2159-63. https://doi.org/10.1589/jpts.28.2159

PMid:27512288

46. Wulandari D, Cahyono HA, Widjajanto E, Puryatni A. Low levels of Vitamin D correlate with hemoglobin A1c and interleukin-10 levels in pediatric Type 1 diabetes mellitus patients. J Trop Life Sci 2014;4(3):182-6. https://doi.org/ 10.11594/jtls.04.03.04

47. Ren Z, Li W, Zhao Q, Ma L, Zhu J. The impact of 1,25-dihydroxy vitamin D3 on the expressions of vascular endothelial growth factor and transforming growth factor- $\beta 1$ in the retinas of rats with diabetes. Diabetes Res Clin Pract 2012;98(3):474-80. https://doi.org/10.1016/j.diabres.2012.09.028

PMid:23089551

48. Geovanini GR, Libby P. Atherosclerosis and inflammation: Overview and updates. Clin Sci (London). 2018;132(12):124352. https://doi.org/10.1042/cs20180306

49. Pillay AK, Naidoo DP. Atherosclerotic disease is the predominant aetiology of acute coronary syndrome in young adults. Cardiovasc J Afr 2018;29(1):36-42. https://doi.org/10.5830/ cvja-2017-035 PMid:29930142

50. Dalla Pozza R, Beyerlein A, Thilmany C, Weissenbacher C Netz $\mathrm{H}$, Schmidt $\mathrm{H}$, et al. The effect of cardiovascular risk factors on the longitudinal evolution of the carotid intima medial thickness in children with Type 1 diabetes mellitus. Cardiovasc Diabetol 2011;10:53. https://doi.org/10.1186/1475-2840-10-53 PMid:21679428

51. Yang SN, Burch ML, Tannock LR, Evanko S, Osman N, Little PJ. Transforming growth factor- $\beta$ regulation of proteoglycan synthesis in vascular smooth muscle: Contribution to lipid binding and accelerated atherosclerosis in diabetes. J Diabetes. 2010;2(4):23342. https://doi.org/10.1111/j.1753-0407.2010.00089.x PMid:20923499 